in the treatment of this condition is lacking, but it is possible that in really adequate dosage it would prove as effective as the less convenient pituitary hormone: a careful trial of early treatment with the oral preparation would be a very suitable project for the Research Committee of the College of General Practitioners.

REFERENCES

Bell, C. (1829). Phil. Trans., 119, 317.

Groves, J. (1965). Arch. Otolaryng., 81, 486.
Hughes, B. (1964). Acute Injuries of the Head, 4th ed., edited by G. F. Rowbotham, p. 428. Edinburgh

Hunt, J. R. (1907). f. nerv. ment. Dis., 34, 73.

Jain, S. N., and Sharma, A. P. (1964). F. Laryng., 78, 266.

Jepsen, O. (1965). Arch. Otolaryng., 81, 446.

Langworth, E. P., and Taverner, D. (1963). Brain, 86, 465.

Rawson, M. D., Liversedge, L. A., and Goldfarb, G. (1966). Lancet, 2, 1044.

Russell, W. R. (1960). Injuries of the Brain and Spinal Cord, and Their Coverings, 4th ed., edited by S. Brock, p. 124. London.

Taverner, D. (1959). Proc. roy. Soc. Med., 52, 1077.

- Fearnley, M. E., Kemble, F., Miles, D. W., and Peiris, O. A (1966). Brit. med. f., 1, 391.

Zilstorff-Pedersen, K. (1965). Arch. Otolaryng., 81, 457.

\title{
Observations on Interpretation of Blood Alcohol Levels Derived from Analysis of Urine
}

\author{
J. P. PAYNE,* M.B., F.F.A. R.C.S., D.A. ; D. V. FOSTER,* T.D., M.R.C.S., L.R.C.P. \\ D. W. HILL,* M.SC., PH.D., F.INST.P., C.ENG., F.I.E.E.; D. G. L. WOOD*
}

Brit. med. F., 1967, 3, 819-823

For many years it has been customary to derive blood alcohol concentrations from the analysis of urine, and despite the fact that the accuracy of such derivations has often been questioned British courts have been content to accept them as evidence in prosecutions for drunken driving, presumably on the grounds that such evidence was merely confirmatory and not vital. However, with the impending change in the law which will make it an offence to drive with more than a stated amount of alcohol in the blood, the reliability of the method of determining blood alcohol concentrations assumes much greater significance, particularly as the use of urine analysis has not been excluded (Ministry of Transport, 1965).

In the interpretation of blood levels derived from urine analysis two problems arise. The first concerns the accuracy of the analytical method used to measure the alcohol concentration in urine, and the second is related to the choice of the conversion factor for the derivation of blood level. In the case of urine analysis the accuracy of the Nickolls modification of the Cavett technique is well established, but the method is tedious, time-consuming, and critically dependent on the technical skill of the operator. Gas chromatography is free from these disadvantages (Chandela and Janák, 1960), and it is claimed that when used in combination with an internal standard and an integrator the alcohol content of a minute sample of either blood or urine can be measured accurately within five minutes (Curry, Walker, and Simpson, 1966). One purpose of the investigation to be described was to determine the accuracy of the gas chromatographic method.

In the case of the conversion factor no unanimity of opinion exists about the correct choice, and it was the second purpose of the investigation to examine the validity of the conversion factor of 1.33 recommended in the Report of a Special Committee of the British Medical Association (1965).

\section{Material and Methods}

During the Christmas period of 1966 and the succeeding, weeks one of us (D.V.F.) in his capacity as police surgeon obtained two specimens of urine at known time intervals and one of venous blood and sometimes one of capillary blood from

\footnotetext{
* Research Department of Anaesthetics, Royal College of Surgeons of England, London W.C.2.
}

35 motorists suspected of driving under the influence of drink. The times at which the samples were obtained were noted and the samples themselves were divided into three equal parts for distribution to the suspect, the police laboratory, and this department. Anonymity was preserved by the designation of a reference number. Initially the samples were analysed both by the Nickolls (1960) modification of the Cavett technique and by the gas chromatographic technique described in detail by Curry et al. (1966) but modified to use a Poropak Q porous polymer bead column instead of a polyethylene glycol 400 column. The Poropak column offers the advantage of a much lower column bleed and elutes the water peak first after 30 seconds followed by ethanol at 1.5 minutes and n-propanol at 3.5 minutes. With polyethylene glycol, unless the column is carefully conditioned with water before use, a tailing water peak is produced which prolongs the analysis. Latterly the samples were analysed by the gas chromatographic method alone.

For chromatographic analysis the blood or urine sample was diluted with ten times its volume of an aqueous solution containing $24 \mathrm{mg}$. of propranol per $100 \mathrm{ml}$. to act as an internal standard. One microlitre $(\mu l$.) of this diluted sample was injected into the Poropak Q chromatographic column maintained at $170^{\circ} \mathrm{C}$. The resultant peaks were detected by a flame ionization detector and the output signals fed into a digital integrator. Whenever possible the analyses were carried out in triplicate.

The accuracies of both the Nickolls and the gas chromatographic methods were tested by analysing samples of pure water and normal blood to which known quantities of alcohol had been added to achieve a range between 52 and $242 \mathrm{mg} . / 100 \mathrm{ml}$. The purity of the absolute alcohol used in the preparation of standards was certified by the Laboratory of the Government Chemist using a refractive index method, as were the dilute solutions of standards. The solutions themselves were prepared by weight by means of an accurate analytical balance to achieve an alcohol content in distilled water which was between 30 and $32 \mathrm{mg} . / \mathrm{ml}$. In the preparation of the blood samples the alcohol solution was added by weight to a flask containing a known weight of blood equivalent to not less than $50 \mathrm{ml}$. The blood itself was magnetically stirred during and after the transfer for five minutes.

When the values for urine and the corresponding venous blood had been obtained it became obvious that additional information on urine:blood ratios would be an advantage. The 
co-operation of the forensic laboratories was sought and $\mathrm{Dr}$ Morgan, of the Department of Industrial and Forensic Sciences in Belfast, supplied values additional to those already published (Morgan, 1965), which allowed a more extensive statistical analysis based on a computer programme specifically designed for the purpose. The programme was used to obtain mean urine and blood values together with their standard deviations, to calculate individual and mean urine:blood ratios, and to determine their distribution. In the case of our own observations a corrected urine: blood ratio was also derived which took into account the time difference between the collection of the venous blood specimens and the corresponding second urine specimens.

Because of the suggestion that capillary blood could provide a satisfactory answer to the problem of blood sampling, both venous blood and capillary blood samples were collected whenever possible. The venous samples were obtained in $20-\mathrm{ml}$. Steriseal syringes from a superficial vein on the forearm after preparing the skin with cetrimide B.P. solution. After collection the samples were decanted into the standard 5-ml. fluorideoxalate bottles available in the police station. The capillary samples were obtained from a stab puncture on the ball of the thumb and collected in capillary tubes or in plastic pots.

Four types of glass capillary tubes were used. The first was the standard straight capillary tube (type D.551) supplied for blood-gas estimations by Radiometer Limited, Copenhagen. These tubes are heparinized, have a capacity of 60-80 $\mu$ l., and are fitted with plastic caps and a magnetic armature to facilitate mixing. The second type was also straight but was larger, with a capacity of $150 \mu \mathrm{l}$., and was coated with fluoride-oxalate. These tubes were manufactured by Harshaw Chemicals Limited, of Daventry, for the East Midland Forensic Science Laboratory. The third type was U-shaped, had a capacity of $140 \mu \mathrm{l}$., and was supplied to the Northern Forensic Science Laboratory by MacFarlane Robson Limited, Blaydon, Newcastle upon Tyne. Fluoride-oxalate was used to prevent clotting in the $U$ tube and also in the fourth type, which was $S$-shaped with a capacity of $150 \mu \mathrm{l}$. The S-shaped tubes were made by Morbank Limited, of Pontypridd, for the Home Office Central Research Establishment. Both the U-shaped and the S-shaped tubes were originally designed to facilitate weighing on a torsion balance in relation to the estimation of blood alcohol content by another technique. The polypropylene plastic pots, which were heparinized, had a capacity of $300 \mu \mathrm{l}$., and were supplied to the North-Western Forensic Science Laboratory by Tinker Grayson Limited, Huddersfield.

Early in the study certain discrepancies were noticed in the determinations of the alcohol content of capillary blood. Because of these discrepancies the co-operation of the Home Office laboratories was again sought, and blood samples collected in capillary tubes and plastic pots from volunteers in this department were distributed to a number of centres for analysis.

On five occasions, in addition to measuring the alcohol concentration in whole blood, that in plasma and in red blood cells was also determined. For this purpose $10-15 \mathrm{ml}$. of the blood sample was placed in a glass test-tube sealed with a groundglass stopper and centrifuged at 2,300 r.p.m. for 20 minutes at room temperature in a Griffin-Christ centrifuge (type UJ 3 ). At the end of this period the separated plasma was pipetted into a second tube, which was then sealed until analysed by gas chromatography. Because the packed cells tended to block the needle of the microsyringe when inserted into the heated inlet tube of the gas chromatograph the alcohol content of the red blood cells was measured by the Nickolls method. Twomillilitre aliquots of undiluted packed cells were used for this analysis; this had the added advantage of eliminating the possible difficulties of handling minute quantities of red blood cells. The haematocrit value for each blood sample was determined and this together with a correction factor for trapped plasma (Chaplin and Mollison, 1952) was used to calculate the alcohol concentration in whole blood.

\section{Results}

\section{Accuracy of Gas Chromatography}

In preliminary studies known amounts of ethanol were added to 15 blood samples to achieve concentrations in the range from 52 to $242 \mathrm{mg} . / 100 \mathrm{ml}$. On analysis $98 \%$ recovery was achieved on average with the Nickolls method, with a correlation coefficient of 0.99 between duplicate samples. The gas chromatograph gave equally satisfactory results; $99 \%$ of the added ethanol was recovered and the correlation coefficient for duplicate samples was again 0.99 .

Known amounts of ethanol were added to water to achieve concentrations between 76 and $197 \mathrm{mg} . / 100 \mathrm{ml}$. and 13 separate samples were analysed in duplicate by the two methods. With the Nickolls method $100 \%$ of the added alcohol was recovered and the correlation coefficient between duplicate samples was 0.99. Gas chromatography was slightly less efficient ; the percentage recovery was 97 and the correlation coefficient 0.97 .

Despite the apparently satisfactory recovery achieved with gas chromatography from blood, the Nickolls method continued to be used during the initial stages of the study of blood and urine obtained from suspects. The first 12 samples were analysed in duplicate by the Nickolls method and in triplicate by gas chromatography. Comparison of the results obtained by the two methods gave a correlation coefficient of 0.99 , and this provided the justification for continuing the study by gas chromatography alone.

\section{Urine : blood Ratios}

The analyses of one blood and two urine samples from 35 suspects gave 70 paired results, and the details are set out in Table I. The mean alcohol concentration of 35 first urine samples was $262 \pm 54 \mathrm{mg} . / 100 \mathrm{ml}$. The corresponding mean

TABLE I.-Measured Alcohol Concentrations in One Blood and Two Urine Samples Collected from 35 Motorists, Together With Derived Values, Ratios, Means, and Standard Deviations

\begin{tabular}{|c|c|c|c|c|c|c|c|c|c|}
\hline 苛 & 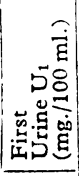 & 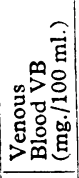 & 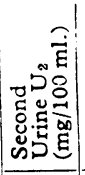 & 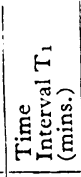 & 点 & 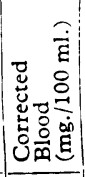 & $\stackrel{\infty}{5}$ & $\frac{9}{\sum_{0}^{\infty}}$ & $\underbrace{0}$ \\
\hline $\begin{array}{r}1 \\
2 \\
3 \\
* 4 \\
5 \\
* 6 \\
* 7 \\
8 \\
* 9 \\
10 \\
11 \\
12 \\
13 \\
14 \\
15 \\
16 \\
17 \\
* 18 \\
19 \\
20 \\
* 21 \\
22 \\
* 23 \\
24 \\
25 \\
26 \\
27 \\
* 28 \\
29 \\
30 \\
* 31 \\
32 \\
33 \\
34 \\
* 35\end{array}$ & $\begin{array}{l}365 \\
270 \\
313 \\
331 \\
150 \\
402 \\
305 \\
207 \\
216 \\
213 \\
293 \\
253 \\
170 \\
356 \\
216 \\
89 \\
331 \\
250 \\
302 \\
175 \\
285 \\
313 \\
150 \\
256 \\
316 \\
305 \\
359 \\
204 \\
305 \\
207 \\
190 \\
256 \\
239 \\
274 \\
289\end{array}$ & $\begin{array}{l}241 \\
178 \\
224 \\
246 \\
109 \\
302 \\
207 \\
127 \\
138 \\
103 \\
190 \\
161 \\
124 \\
239 \\
109 \\
40 \\
210 \\
195 \\
239 \\
103 \\
184 \\
213 \\
184 \\
178 \\
127 \\
201 \\
270 \\
164 \\
262 \\
150 \\
230 \\
193 \\
167 \\
207 \\
194\end{array}$ & $\begin{array}{l}365 \\
253 \\
296 \\
339 \\
132 \\
405 \\
310 \\
187 \\
230 \\
190 \\
265 \\
224 \\
161 \\
336 \\
172 \\
54 \\
328 \\
267 \\
287 \\
170 \\
293 \\
279 \\
230 \\
253 \\
310 \\
305 \\
359 \\
213 \\
287 \\
207 \\
296 \\
253 \\
230 \\
264 \\
294\end{array}$ & $\begin{array}{l}60 \\
55 \\
44 \\
65 \\
45 \\
67 \\
40 \\
50 \\
30 \\
39 \\
31 \\
36 \\
45 \\
34 \\
30 \\
35 \\
46 \\
40 \\
45 \\
25 \\
46 \\
50 \\
50 \\
41 \\
26 \\
25 \\
61 \\
49 \\
50 \\
32 \\
35 \\
30 \\
55 \\
35 \\
40\end{array}$ & $\begin{array}{r}-13 \\
35 \\
5 \\
15 \\
37 \\
37 \\
30 \\
20 \\
-11 \\
16 \\
16 \\
29 \\
22 \\
21 \\
-25 \\
-15 \\
56 \\
-3 \\
33 \\
-16 \\
19 \\
16 \\
28 \\
20 \\
-12 \\
-22 \\
23 \\
52 \\
18 \\
22 \\
10 \\
8 \\
15 \\
12 \\
-10\end{array}$ & $\begin{array}{r}236 \\
164 \\
222 \\
240 \\
94 \\
287 \\
195 \\
119 \\
134 \\
97 \\
184 \\
149 \\
115 \\
231 \\
99 \\
34 \\
196 \\
192 \\
226 \\
97 \\
176 \\
207 \\
173 \\
170 \\
122 \\
192 \\
261 \\
143 \\
255 \\
141 \\
226 \\
190 \\
161 \\
202 \\
190\end{array}$ & $\begin{array}{l}1.51 \\
1.52 \\
1.40 \\
1.35 \\
1.35 \\
1.33 \\
1.47 \\
1.63 \\
1.57 \\
2.07 \\
1.54 \\
1.57 \\
1.37 \\
1.49 \\
1.98 \\
2.22 \\
1.52 \\
1.28 \\
1.26 \\
1.70 \\
1.53 \\
1.47 \\
0.82 \\
1.44 \\
2.59 \\
1.52 \\
1.33 \\
1.24 \\
1.16 \\
1.38 \\
0.83 \\
1.33 \\
1.43 \\
1.32 \\
1.49\end{array}$ & $\begin{array}{l}1.51 \\
1.42 \\
1.32 \\
1.38 \\
1.21 \\
1.34 \\
1.50 \\
1.47 \\
1.67 \\
1.84 \\
1.39 \\
1.39 \\
1.30 \\
1.41 \\
1.58 \\
1.35 \\
1.50 \\
1.37 \\
1.20 \\
1.65 \\
1.59 \\
1.31 \\
1.25 \\
1.42 \\
2.44 \\
1.52 \\
1.33 \\
1.30 \\
1.10 \\
1.38 \\
1.29 \\
1.31 \\
1.38 \\
1.28 \\
1.52\end{array}$ & $\begin{array}{l}1.00 \\
1.07 \\
1.06 \\
0.98 \\
1.14 \\
0.99 \\
0.98 \\
1.11 \\
0.94 \\
1.12 \\
1.11 \\
1.13 \\
1.06 \\
1.06 \\
1.26 \\
1.65 \\
1.01 \\
0.91 \\
1.05 \\
1.03 \\
0.98 \\
1.12 \\
0.65 \\
1.01 \\
1.02 \\
1.00 \\
1.00 \\
0.96 \\
1.05 \\
1.00 \\
0.64 \\
1.01 \\
1.01 \\
1.04 \\
0.99\end{array}$ \\
\hline D. & $\begin{array}{r}262 \\
54\end{array}$ & $\begin{array}{r}183 \\
55\end{array}$ & $\begin{array}{r}258 \\
71\end{array}$ & & & & 1.43 & $1 \cdot 41$ & \\
\hline
\end{tabular}

- Indicates second urine samples collected without evidence that the peak concentration had been reached.

$T_{1}$ Time interval between collection of first and second urine samples.

$T_{2}$ Time interval between collection of blood sample and second urine sample. A ne 
for the second urine samples was $258 \pm 71 \mathrm{mg} . / 100 \mathrm{ml}$., and the mean venous blood value was $183 \pm 55 \mathrm{mg} . / 100 \mathrm{ml}$. When both first and second urine values are used these figures give an overall urine: blood ratio of $1.42: 1$. Of the 35 second urine samples analysed 25 were collected after the peak alcohol concentration in urine had been reached. When these were related to the corresponding blood values a mean urine: blood ratio of $1.44: 1$ was obtained. However, individual ratios in this second group varied from 1.10 to $2.44: 1$, and the range was even greater in the first group, from 0.82 to 2.59 .

An attempt at back-calculation was made. For this purpose the alcohol clearance from the blood was derived from values obtained in a previous study (Payne, Hill, and King, 1966). Results from 16 volunteers were analysed, and it was found that the rate of clearance varied between 10 and $38 \mathrm{mg} . / 100$ $\mathrm{ml}$./hour, with a mean value of $24 \mathrm{mg}$. No correlation with the weight of the subject could be obtained. The mean value was used to derive a corrected urine:blood ratio of 1.48 .

From the 518 paired urine and blood results made available from Belfast the mean urine:blood ratio was 1.38. The distribution of these ratios is set out in the Chart. Just over

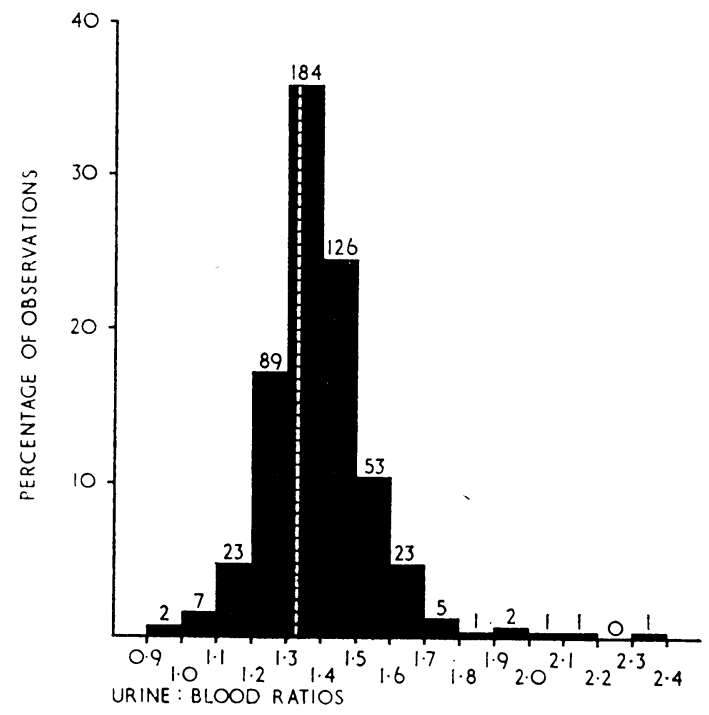

Percentage distribution of the urine:blood ratios derived from Belfast data. The figures at each step denote the actual number of ratios determined. The dotted line indicates the urine to blood ratio of 1.33 .

$35 \%$ of these results fall into the ratio range of $1.30-1.39: 1$. The range of urine values was from 43 to $481 \mathrm{mg} . / 100 \mathrm{ml}$., and the urine: blood ratios extended from $0.92: 1$ to $2.32: 1$.

\section{Capillary Blood Analysis}

In most instances the alcohol content of the capillary blood was substantially below that of the corresponding venous blood. In the case of the straight tubes 10 separate samples contained, on average, $61 \%$ of the alcohol content found in the corresponding venous blood. When the $U$ tubes were used 10 tubes contained an average of $79 \%$ of the alcohol content of the corresponding venous blood. Of 10 samples collected in S-shaped tubes six contained, on average, only $53 \%$ of the alcohol content of the corresponding venous sample; the remaining four tubes had an alcohol content $7 \%$ higher than the venous blood. The capillary blood collected in the 11 plastic pots had a higher average alcohol concentration than that of the tubes but still contained only $90 \%$ of that found in the corresponding venous blood.

Of the limited number of capillary tubes and polypropylene pots distributed to other departments, only the samples stored in the pots gave good agreement on analyses. There were wide discrepancies in the results obtained from the capillary tubes.

\section{Plasma : Red Blood Cell Ratios}

The distribution of alcohol in the plasma and packed cells of whole blood was studied in five venous samples, and the relevant data are set out in Table II. The calculated alcohol content of whole blood in column 5 , derived by measuring the packed cell volume and the alcohol content of both plasma and red blood cells, largely confirmed the accuracy of the methods used. A mean plasma: red blood cell ratio of 1.43:1 was obtained and a somewhat lower ratio of $1.15: 1$ expressed the relation between plasma and whole blood.

TABLE II.-Difference in Alcohol Content Between Whole Blood, Plasma and Red Blood Cells. The Calculated Whole Blood Content was Derived From That of the Plasma and Red Blood Cells by Means of the Haematocrit

\begin{tabular}{|c|c|c|c|c|c|c|}
\hline \multirow{2}{*}{$\begin{array}{l}\text { Haemato- } \\
\text { crit } \\
\text { (1) }\end{array}$} & \multicolumn{4}{|c|}{ Alcohol Content (mg. $/ 100 \mathrm{ml}$.) } & \multicolumn{2}{|c|}{ Ratios } \\
\hline & $\begin{array}{c}\text { Whole } \\
\text { Blood } \\
\text { (2) }\end{array}$ & $\begin{array}{c}\text { Plasma } \\
\text { (3) }\end{array}$ & $\begin{array}{c}\text { R.B.C.s } \\
\text { (4) }\end{array}$ & $\begin{array}{c}\text { Calculated } \\
\text { Whole } \\
\text { Blood } \\
(5)\end{array}$ & $\begin{array}{c}\text { Plasma: } \\
\text { R.B.C.s } \\
\text { (6) }\end{array}$ & $\begin{array}{c}\text { Plasma: } \\
\text { Whole } \\
\text { Blood } \\
(7)\end{array}$ \\
\hline $\begin{array}{l}45 \\
43 \\
42 \\
44 \\
42\end{array}$ & $\begin{array}{l}117 \\
151 \\
181 \\
125 \\
194\end{array}$ & $\begin{array}{l}132 \\
173 \\
217 \\
144 \\
217\end{array}$ & $\begin{array}{r}93 \\
124 \\
146 \\
102 \\
152\end{array}$ & $\begin{array}{l}115 \\
151 \\
187 \\
126 \\
190\end{array}$ & $\begin{array}{l}1 \cdot 41 / 1 \\
1.40 / 1 \\
1.49 / 1 \\
1.41 / 1 \\
1 \cdot 43 / 1\end{array}$ & $\begin{array}{l}1 / 13 \cdot 1 \\
1 \cdot 15 / 1 \\
1 \cdot 20 / 1 \\
1 \cdot 15 / 1 \\
1 \cdot 12 / 1\end{array}$ \\
\hline
\end{tabular}

\section{Discussion}

The conclusion by Curry et al. (1966) that when gas chromatography is combined with an internal standard and an integrator the alcohol content of small samples of body fluid can be measured accurately within five minutes has been substantiated.

The fact that the alcohol content of urine can be measured accurately does not necessarily mean that an exact determination of the amount of alcohol present in blood can be derived from urine analysis. The considerable difference of opinion on the correct conversion factor to be used implies a degree of uncertainty that is amply justified by experiment. On the basis of more than 7,000 analyses of urine and the corresponding blood samples Froentjes (1963) calculated the ratio of urine alcohol to blood alcohol as $1.52: 1$. He emphasized, however, that if this conversion factor was applied a $50 \%$ chance existed that the actual blood alcohol concentration would be lower than the calculated value, and for this reason in practice he advocated the use of a conversion factor of $2: 1$. Notwithstanding Froentjes's views the special committee of the British Medical Association set up to consider the problem of the drinking driver came to the conclusion that once the peak concentration in the urine had been passed a urine to blood ratio of $1.32: 1$ could be adopted. Using this ratio, Payne et al. (1966) demonstrated good agreement between urine and blood analyses when studying the uptake, distribution, and elimination of alcohol in a group of healthy volunteers. But these results were obtained under well-controlled conditions in the laboratory, and the present work, confirming that of Stevens, Mason, and Bowden (1966), shows that it would be invalid to use this factor in the less rigidly controlled environment of a busy police station.

That this is so is apparent from the data presented. Of the 518 paired urine and blood samples analysed in Belfast an overall urine:blood ratio of $1.38: 1$ was obtained, but only $35 \%$ fell into the range from 1.30 to $1.39: 1$, and the remainder extended from 0.92 to $2.32: 1$.

Further evidence of the variation in urine: blood ratios was obtained from the analyses of the blood and urine samples presented in Table I. Of the 35 second urine samples obtained from detained motorists, 25 had an alcohol concentration equal to or lower than the first, and were therefore to be regarded as having been collected after the peak concentration in urine had been passed. The significance of this has been discussed by Payne et al. (1966). These values gave a mean ratio of 
$1.44: 1$, somewhat higher than the 1.32 recommended by the special committee of the B.M.A. In only one of these 25 suspects was a precise urine:blood ratio of $1.32: 1$ obtained, and the range was from 1.10 to 2.44 , substantially greater than that of $1.2: 1$ to $1.4: 1$ quoted in the B.M.A. report. The overall mean ratio for the second urine samples was 1.41 . Furthermore, as has been shown previously (Payne et al., 1966), it is apparent from the data in Table I that the urine:blood ratio is not even constant for one individual but varies with time.

The argument is of considerable practical importance; for example, if the urine analysis of Subject No. 10 in Table I had given a value of between 110 and $150 \mathrm{mg} . / 100 \mathrm{ml}$. the use of the conversion factor of 1.32 would yield a blood alcohol concentration of between 82 and $112 \mathrm{mg} . / 100 \mathrm{ml}$., a level which almost certainly would lead to his conviction under the new Act. But in this particular individual the urine:blood ratio was measured and found to be $1.84: 1$, which under the circumstances described yields an actual blood concentration between 60 and $80 \mathrm{mg} . / 100 \mathrm{ml}$., a level below the maximum envisaged as compatible with safe driving in the White Paper on Road Safety Legislation (Ministry of Transport, 1965). In the case of Subject No. 25, whose urine:blood ratio was $2.44: 1$, the discrepancies would have been greater. Thus the suggestion by the Special Committee of the B.M.A. that any injustice to individuals was extremely unlikely when a urine to blood ratio of $1.33: 1$ has been used will certainly cease to be true if present proposals become law. (The B.M.A. report used the factors 1.32 and 1.33 at various times.) Indeed there is every likelihood that the uncritical acceptance of a urine to blood ratio of $1.33: 1$ will lead to miscarriages of justice when it becomes an offence to drive or to be in charge of a motor vehicle with more than a stipulated amount of alcohol in the blood.

As might have been expected from the variation in the rate of removal of alcohol from blood the attempt at back calculation not only failed to bring the urine to blood ratio closer to $1.33: 1$, it also confirmed the difficulty of interpolating accurately a blood alcohol level to an earlier point in time.

The failure to obtain definitive results from urine analysis focused attention once again on blood. The lack of enthusiasm among doctors for venepuncture combined with the convenience and accuracy of gas chromatography suggested that capillary blood analysis might prove an acceptable compromise. Unfortunately, most capillary blood samples were found on analysis to contain substantially lower alcohol concentrations than the corresponding venous samples. Two possibilities existed: either the alcohol concentration in capillary blood was in fact lower than in the corresponding venous blood, or some of the alcohol content was lost after the blood was shed. Since Harger (1963) and his colleagues have shown that the alcohol content of capillary blood is not lower than that of venous blood, it must be accepted that loss has occurred.

The most likely time for such loss is during collection, especially if the flow of blood is too slow to allow rapid filling of the capillary tube ; ethyl alcohol is sufficiently volatile to be lost fairly rapidly from exposed blood at body temperature. Another possible source of loss is from the capillary tube, either by a leak past the plastic seal or by adsorption by the seal itself; plastic materials have recently been shown to interfere with several blood constituents (Whitehead, 1967, personal communication). The capillary tubes themselves were glass, so that loss through the walls was unlikely. When polypropylene pots were used to collect capillary blood the alcohol content of the samples was closer to the venous level than was that in the capillary tubes, but some loss was apparent and it is possible that adsorption on the walls or even diffusion through them had taken place. However, the fact that good agreement was obtained when separate aliquots of the same samples were analysed by different laboratories suggests that the loss probably occurs during sampling rather than during storage in the pot.
During the investigation of this loss it was observed that the blood in some S-shaped and U-shaped eapillary tubes had a substantially higher alcohol content than the corresponding venous blood. These high contents were associated with separation of plasma from red cells within the tube, with problems of mixing and with subsequent difficulties in obtaining good agreement on duplicate analyses; therefore the possibility that alcohol was distributed unevenly between plasma and red blood cells was considered. Definitive information on this aspect is limited; however, Grüner (1957) has shown that alcohol is distributed in human plasma and in whole blood in a ratio of $1.15: 1$, and is dependent on the distribution of water as suggested by the work of Polonovski, Lindenberg, and Rabussier (1951) on dogs. The evidence reported here confirms and amplifies these observations.

The fact that human plasma contains about $40 \%$ more alcohol than an equal volume of red blood cells would explain the high alcohol content in some capillary tubes, but it also raises new problems. In particular, it implies that certain accepted standards such as the urine to blood ratio and the blood to breath ratio cannot be constant, but must be related to the haematocrit. It also implies that the plasma alcohol concentration might be a more useful determination for future experimental work if it is assumed that tissue levels are in equilibrium with the plasma. It would certainly help to explain the difficulties that have been encountered in seeking an answer to the apparent discrepancies in the blood:breath ratio.

\section{Conclusions}

From the data presented certain conclusions can be drawn.

Firstly, the fact that the urine to blood ratio is not constant at 1.33:1 means that an accurate estimation of a blood alcohol level cannot be derived from the analysis of urine with any degree of certainty when a urine to blood ratio of $1.33: 1$ is used.

Secondly, the difficulties encountered in the analysis of capillary blood suggest that the determination of blood alcohol levels should be carried out on venous blood until these difficulties have been overcome. The possibility that unsatisfactory handling techniques are involved emphasizes the need to establish a standard protocol for the withdrawal and handling of blood for the determination of alcohol levels.

Thirdly, the demonstration that human plasma contains about $40 \%$ more alcohol than an equal volume of red blood cells strengthens the argument for such a protocol. It also implies that the alcohol concentration might be better measured in plasma rather than in blood in experimental studies.

\section{Summary}

The fact that gas chromatography when combined with an internal standard and an integrator will measure the alcohol content in minute samples of body fluids rapidly and accurately has been confirmed.

The analysis of blood and urine samples from 35 motorists suspected of driving while under the influence of drink gave a mean urine to blood ratio of $1.44: 1$, substantially higher than the recommended conversion factor of $1.33: 1$. Moreover the range of values found-from 1.10 to $2.44: 1$ - suggests that the uncritical acceptance of this urine to blood ratio of $1.33: 1$ will lead to miscarriages of justice when it becomes an offence to drive or to be in charge of a motor vehicle with more than a stipulated amount of alcohol in the blood.

The failure to obtain good agreement between capillary blood samples and the corresponding venous samples when analysed for alcohol indicates that it would be unwise to depend on capillary blood analysis for accurate results at the present moment. Probably the discrepancies are due to sample- 
handling difficulties, which may be overcome with more experience.

The analysis of five samples of human blood showed that when alcohol is present the plasma contains over $40 \%$ more than whole blood (plasma to R.B.C. ratio, 1.43:1 ; plasma to whole blood ratio, $1.15: 1$ ). Thus the alcohol content of a given blood sample will be critically dependent on the separation or otherwise of plasma from red blood cells during handling.

We are indebted to the directors of the Metropolitan Police Laboratory ; the Home Office Central Research Establishment ; the North-Western (Preston), the Northern (Newcastle), and the East Midland (Nottingham) Forensic Science Laboratories ; and the Department of Industrial and Forensic Science (Belfast) for their cooperation. We are also grateful to Professor F. E. Camps and Dr. E. G. Davies for advice and criticism.

\section{Addendum}

Since this paper was written the Road Safety Act 1967 has been published. In section 7 subsection (4) it is stated that "For the purposes of this Part of this Act 107 milligrammes of alcohol in 100 millilitres of urine shall be treated as equivalent to 80 milligrammes of alcohol in 100 millilitres of blood."

What in effect this means is that it becomes an offence to drive or to be in charge of a motor vehicle when the alcohol content of the urine is $108 \mathrm{mg} . / 100 \mathrm{ml}$. or more. But of the 35 suspects studied in our series no fewer than 19 would have had less than $80 \mathrm{mg}$. of alcohol per $100 \mathrm{ml}$. in blood when the equivalent urine sample contained $108 \mathrm{mg} . / 100 \mathrm{ml}$; indeed subject No. 25, whose urine to blood ratio was $2.44: 1$, would have a blood level of only $44.3 \mathrm{mg}$. of alcohol per $100 \mathrm{ml}$. at this urine level.

Thus the warning given in our paper that the uncritical acceptance of a urine to blood ratio of $1.33: 1$ will lead to miscarriages of justice when it becomes an offence to drive or to be in charge of a motor vehicle with more than a stipulated amount of alcohol in the blood is entirely justified. In the interests of justice therefore suspected drivers would be well advised to insist on a blood specimen being taken if asked to provide a sample of urine for examination.

\section{REFERENCES}

B.M.A. Special Report (1965). The Drinking Driver. London. Chaplin, H., jun., and Mollison, P. L. (1952). Blood, 7, 1227. Chundela, B., and Janák, J. (1960). f. forens. Med., 7, 153 . Curry, A. S., Walker, G. W., and Simpson, G. S. (1966). Analyst, 91, 742.

Froentjes, W. (1963). In Alcohol and Road Traffic, p. 179. London. Grüner, O. (1957). Dtsch. Z. ges. gerichtl. Med., 46, 10.

Harger, R. N. (1963). In Alcohol and Road Traffic, p. 212. London. Ministry of Transport (1965). Road Safety Legislation, 1965-6, p. 12. London.

Morgan, W. H. D. (1965). 7. forens. Sci. Soc., 5, 15.

Nickolls, L. C. (1960). Analyst, 85, 840.

Payne, J. P., Hill, D. W., and King, N. W. (1966). Brit. med. F., 1, 196.

Payne, J. P., H., Lindenberg, B. A., and Rabussier, H. (1951). C.R. Acad. Sci. (Paris), 232, 1595 .

Stevens, P. J., Mason, J. K., and Bowden, C. H. (1966). Med. Sci. Law, 6, 96.

\begin{abstract}
P. J. S. HAMILTON,* M.B., D.P.H., D.T.M.\&H. ; JOHN RICHMOND, $\dagger$ M.D., F.R.C.P.ED., M.R.C.P. G. W. K. DONALDSON, $\ddagger$ M.B., B.SC., M.R.C.P., M.R.C.P.ED. ; ROGER WILLIAMS,§ M.D., M.R.C.P. M. S. R. HUTT, \| M.D., F.R.C.P., F.C.PATH. ; V. LUGUMBAg
\end{abstract}

Brit. med. F., 1967, 3, 823-825.

Idiopathic or cryptogenic tropical splenomegaly is sometimes treated empirically by splenectomy. Moreover, in areas where this condition is commonly encountered medical facilities are usually not available for the full investigation of such cases before or after splenectomy. Recently, a group of patients suffering from idiopathic tropical splenomegaly were studied in detail in the Mulago Hospital, Kampala, Uganda. All known causes of tropical splenomegaly were excluded in these patients, who on liver biopsy showed varying degrees of lymphocytic infiltration of the liver sinusoids and Kupffer-cell hyperplasia. In addition they all had high fluorescent antibody titres for malaria. This association is known locally as "big spleen disease" (Hamilton et al., 1966) and is referred to by that title in this paper. Williams et al. (1966) showed in haemodynamic studies that these patients suffered from considerable portal hypertension, apparently due to increased spleen blood flow.

* Late Lecturer in Medicine, Makerere University College Medical School, Kampala, Uganda. On secondment from London School of Hygiene and Tropical Medicine. Present address: London School of Hygiene and Tropical Medicine, Keppel Street, London W.C.1.

+ Senior Lecturer in Medicine, Department of Medicine, University of Edinburgh.

₹ Lecturer in Medicine, Department of Medicine, University of Edinburgh.

Physician and Medical Tutor, King's College Hospital, London S.E.5. rofessor of Pathology, Makerere University College Medical School, Kampala, Uganda.

I Social Worker, Makerere University College Medical School, Kampala,
Richmond et al. (1967), reporting the haematological findings on the same group of patients, found that they all had anaemia, sometimes of severe degree, and this appeared to be due to sequestration of a large proportion of the red cell mass in the spleen, expansion of the plasma volume, and reduction of the red cell life-span. Seven of the 15 patients were treated by splenectomy in June-July 1965, the indications for splenectomy being either incapacitating abdominal pain or discomfort or the finding of pronounced hypervolaemia with anaemia. Follow-up studies on these seven patients two months after splenectomy showed satisfactory improvement in the haemoglobin level in six of them and correction of the red cell survival time in the four in whom this was measured.

This paper describes follow-up studies on five of the splenectomized patients 15 months after the operation.

\section{Patients and Methods}

Six of the seven patients splenectomized in June-July 1965 were traced to their homes in October 1966 by one of us (V.L.) ; one patient, who was in good health, could not be traced. Five patients were studied in detail.

All were males aged 20-55 years. Full clinical examination, routine haematological tests (Dacie and Lewis, 1963), standard liver-function tests, and brucella and salmonella serum agglu- 